\title{
20 Sensory nerve supply of the ear
}

A The lesser occipital nerve (C1) supplies the upper medial surface of the pinna.

B The 'Alderman's nerve' may be stimulated by instilling spirit or instruments into the external meatus.

C The glossopharyngeal nerve supplies sensory fibres to the middle ear cleft.

D The mandibular nerve supplies sensation to the lateral surface of the pinna and the anterior halves of the external meatus and tympanic membrane.

E The seventh cranial nerve gives a sensory supply to the ear.

\section{The following lesions may cause referred otalgia}

A Fibrositis of the upper portion of the sternomastoid muscle via the fibres of $\mathrm{C} 2$ and $\mathrm{C} 3$.

B A high septal deviation causing pressure on the middle turbinate.

C Parotid and submandibular calculi.

D Acute sphenoidal and maxillary sinusitis.

E An elongated styloid process.

\section{The following neoplasms may present with otalgia}
A Nasopharyngeal carcinoma.
B Tonsillar carcinoma.
C Oesophageal carcinoma
D Oropharyngeal carcinoma.
E Chemodectoma of the larynx. 